\title{
ISOLATION OF FUNGI FROM ADULT HOUSE FLY; MUSCA DOMESTICA AND THE BLOW FLY Chrysomya megacephala IN UBON RATCHATHANI PROVINCE, NORTHEASTERN THAILAND
}

\author{
THANYAKARN SRIVORAMAS1, TARINEE CHAIWONG1 AND MICHELLE R. SANFORD² \\ ${ }^{1}$ College of Medicine and Public Health, Ubon Ratchathani University, Warinchamrap, Ubon Ratchathani, 34190, Thailand \\ 2Pathology, Microbiology and immunology, University of California, Davis, California 95616, USA \\ *Corresponding Author: thanya.sr@hotmail.com
}

Received: February 05, 2012; Accepted: February 16, 2012

\begin{abstract}
The aim of this study was to isolate and identify fungi on the external surfaces of adult house fly, Musca domestica and the blow fly, Chrysomya megacephala. These flies were collected from two districts in Northeastern Thailand: Muang and Warinchamrap in Ubon Ratchathani province, in September 2010. The main fungi isolated were Mucorales, followed by Yeast, Aspergillus niger and Penicillium spp. However, various species were identified including Aspergillus fumigatus, Gliocladium spp., Fusarium spp., Drechslera spp., Scedosporium apiospermum, Cladosporium spp. and Nocardia spp. This study demonstrated that both adult; $M$. domestica and $C$. megacephala have the ability to function as carriers for fungal spores and might be important in the transmission of fungi to humans in this area.
\end{abstract}

Key words - Musca domestica, Chrysomya megacephala, Fungi, Isolation.

Citation: Thanyakarn Srivoramas, Tarinee Chaiwong and Michelle R. Sanford. (2012) Isolation of fungi from adult house fly; Musca domestica and the blow fly Chrysomya megacephala in Ubon Ratchathani Province, Northeastern Thailand. International Journal of Parasitology Research, ISSN: 0975-3702 \& E-ISSN: 0975-9182, Volume 4, Issue 1, 2012, pp.-53-56.

Copyright: Copyright@2012 Thanyakarn Srivoramas, et al. This is an open-access article distributed under the terms of the Creative Commons Attribution License, which permits unrestricted use, distribution, and reproduction in any medium, provided the original author and source are credited.

\section{Introduction}

Musca domestica, commonly known as the house fly is a cosmopolitan species that lives in close association with human dwellings. It is probably the most widely distributed domestic insect species in the world [1]. In Thailand, it is one of the most abundant fly species collected ( $\sim 90 \%$ of collections) in several areas of the country including the Chiang Mai province [2-4].

Chrysomya megacephala is a blow fly in the family Calliphoridae, commonly known as the Oriental latrine fly. C. megacephala is widely distributed throughout Asia, Australasia, the Pacific Region, South Africa and South America [5,6]. In Thailand, it is the second most abundant fly species collected, but is ranked among the most frequently collected blow fly species $[2,4,7]$.

The greatest medical importance of $M$. domestica and $C$. megacephala is their ability to function as mechanical vectors of various pathogens that may cause disease in humans. By crawling over and feeding on filth, flies become contaminated with pathogens that become entrapped on their legs and body surfaces or take them into the digestive tract with food. In later visits to human food, flies leave behind some of these pathogens. Their habit of regurgitating some of their food and expelling feces frequently, both of which may contain pathogens, contaminates food, food preparation surfaces and storage containers used for human consumption. Also, there is evidence that larvae feeding on infected material can produce infected adults [8].

Both $M$. domestica and $C$. megacephala have been found to spread the etiological agents of typhoid and paratyphoid fevers, bacillary dysentery, cholera, hematic carbuncles,

bovine mastitis (garget), conjunctivitis and poliomyelitis [1]. These fly species have also been reported capable of carrying cysts of many protozoans, such as Entamoeba histolytica, Entamoeba coli, Giardia intestinalis, as well as the eggs of some helminthes [9].

Vectors like rodents and insects, especially house flies, have been 
Isolation of fungi from adult house fly; Musca domestica and the blow fly Chrysomya megacephala in Ubon Ratchathani Province, Northeastern Thailand

reported as carriers of yeast and filamentous fungi. The association of insects and fungi has been confirmed by several reports [10 -12]. Butcher shops are important sources of contamination of the house flies surface with fungi. Dirt, soil, body discharges and excreta from animals in holding pens are the main sources of fungal contamination of house-flies [13].

Various studies have reported the isolation of fungi from insects. Burnside [14] isolated Aspergillus flavus, Aspergillus niger and Penicillium corylophilum from bees. Gillian and Prest [15] and Gillian $\mathrm{M}$ et al. [11] also isolated various fungi from bees, identifying the species A. niger, A. flavus, P. corylophilum, Cladosporium ladosporoides and Alternaria spp. Costa and Oliveira [12] isolated various species of Penicillium from mosquito vectors of tropical diseases. With respect to flies associated with filth, Norberg et al. [16] verified the predominance of the genus Penicillium in adult Muscidae ( $M$. domestica among others), captured in hospitals, bars and outdoor markets in the back-bay lowlands surrounding Rio de Janeiro, Brazil. These authors also reported the isolation of other species, such as: A. fumigatus, A. niger, Fusarium sp., Alternaria sp. and Candida albicans, among the most frequent. In another work on isolation and identification of fungi in muscid flies, Kaaya and Okech [17] reported various species isolated from pupal and adult Glossina pallidipes, including A. flavus, A. niger, Penicillium spp. and Fusarium spp.. Adult M. domestica collected from two natural breeding sites: hog pens and an urban sanitary landfill, Márcia de Senna Nunes Sales et al.[9] identified the isolated fungi as: A. flavus, A. niger var. niger, $P$. corylophilum, $P$. fellutanum, Cladosporium cladosporoides, Fusarium spp. Alternaria alternata, Curvularia brachyspora, Mycelia sterilia and the Mucorales order. Banjo et al. [18] isolated Alternaria spp., Penicillum oxalicum and Aspergillus tamari from housefly (M. domestica L.) larvae. These authors also reported the isolation of other species, such as: Neurospra sp, Alternaria spp. and Fusarium oxysporium from the larvae of the sheep blow fly Lucilia cuprina [19]. Majid Zarrin et al. [13] identified fungi from the external surface of house flies in Ahwaz, Iran as: species of Aspergillus, Penicillium, Yeasts, Cladosporium and Fusarium. This also included two species of dermatophytes, Microsporum gypseum and Trichophyton mentagrophytes.

In Northeastern Thailand, there have been few studies and there is a lack of knowledge regarding the fungal species that have an association with these insects. The objective of this study was to isolate and identify fungi on the external surfaces of adult house fly, M. domestica and the blow fly, C. megacephala in the Ubon Ratchathani province of Northeastern Thailand.

\section{Methodology}

\section{Collection of flies}

Adult $M$. domestica and C. megacephala were collected at two districts (Muang and Warinchamrap) in Ubon Ratchathani province in Northeastern Thailand, in September 2010. The collection sites in each district were selected to include fresh-food markets, garbage piles, restaurants, school cafeterias and rice paddy fields. The temperature and relative humidity were obtained from the Northeastern Meteorological Center, Ubon Ratchathani, Thailand: Muang Ubon Ratchathani district; $25.73{ }^{\circ} \mathrm{C}$ and $71 \%$, Warinchamrap district; $28.1^{\circ} \mathrm{C}$ and $62 \%$ ). Flies were captured with a sterile insect sweep net individually. Each specimen transferred into an individual $20 \mathrm{ml}$ sterile glass vial $(2.5 \mathrm{~cm}$. diameter, $6 \mathrm{~cm}$. height) using sterile forceps. After capture, the vials containing flies transported within one hour to the College of Medicine and Public Health, Ubon Ratchathani University. In the laboratory, all fly specimens killed by placing them into a freezer set at $-70{ }^{\circ} \mathrm{C}$ for $15 \mathrm{~min}$. All the instruments and culture media used in this step were previously sterilized in an autoclave.

\section{Isolation of fungi}

Two milliliters of sterile buffer peptone water was added to each vial and then shaken vigorously for 2 minutes to create a wash from each fly. Subsequently, $0.1 \mathrm{ml}$ of the wash solution vial was inoculated onto Sabouraud's dextrose agar (SDA) media plates containing chloramphenical to inhibit bacterial growth. The plates were kept at room temperature for fungal growth $\left(20-25^{\circ} \mathrm{C}\right.$.)

\section{Identification of fungi}

The fungi were identified using a light microscope. The samples were stained with lactophenal cotton blue for mounting between the slides and slide covers. If it was necessary, the slide culture was used for confirmation the species [20].

\section{Results}

Fungi were examined from a total of 36 flies during this study. Approximately 57 fungal isolates were made from the external surfaces of the flies comprising twelve different fungal groups (Table-1).

Mucorales (28\%), Yeast (19\%), A. niger (16\%) and Penicillium spp. (11\%) were most commonly isolated. The other detected fungi were: A. fumigatus (5\%), Gliocladium spp. (4\%), Fusarium spp. (5\%), Drechslera spp. (4\%), Scedosporium apiospermum (1\%), Cladosporium spp. (1\%) and Nocardia spp. (1\%).

Table 1- Fungi isolated from the external surfaces of $M$. domestica (MD) and C. megacephala (CM) in Muang Ubon Ratchathani and Warinchamrap districts, Ubon Ratchathani province, Northeastern Thailand.

\begin{tabular}{|c|c|c|c|c|c|}
\hline \multirow{3}{*}{ Fungi } & \multicolumn{5}{|c|}{ Number isolates (\%) } \\
\hline & \multicolumn{2}{|c|}{$\begin{array}{l}\text { Muang Ubon } \\
\text { Ratchathani district }\end{array}$} & \multicolumn{2}{|c|}{$\begin{array}{l}\text { Warinchamrap } \\
\text { district }\end{array}$} & \multirow{2}{*}{ Total } \\
\hline & MD & $\mathrm{CM}$ & MD & CM & \\
\hline Mucorales & $5(42)$ & $2(18)$ & $4(18)$ & $5(42)$ & $16(28)$ \\
\hline Yeast & $5(42)$ & $2(18)$ & $4(18)$ & 0 & $11(19)$ \\
\hline Aspergillus niger & $1(8)$ & $4(36)$ & $2(9)$ & $2(17)$ & $9(16)$ \\
\hline Aspergillus fumigatus & 0 & 0 & $3(14)$ & 0 & $3(5)$ \\
\hline Penicillium spp. & 0 & $1(9)$ & $4(18)$ & $1(8)$ & $6(11)$ \\
\hline Gliocladium spp. & 0 & 0 & $1(5)$ & $1(8)$ & $2(4)$ \\
\hline Fusarium spp. & 0 & 0 & $2(9)$ & $1(8)$ & $3(5)$ \\
\hline Drechslera spp. & 0 & 0 & $1(5)$ & $1(8)$ & $2(4)$ \\
\hline Curvularia spp. & 0 & 0 & $1(5)$ & $1(8)$ & $2(4)$ \\
\hline Scedosporium apiospermum & $1(8)$ & 0 & 0 & 0 & $1(2)$ \\
\hline Cladosporium spp. & 0 & $1(9)$ & 0 & 0 & $1(2)$ \\
\hline Nocardia spp. & 0 & $1(9)$ & 0 & 0 & $1(2)$ \\
\hline Total & 12 & 11 & 22 & 12 & 57 \\
\hline
\end{tabular}

\section{Muang Ubon Ratchathani district}

The isolated fungi were identified from $M$. domestica as: Mucorales (42\%), Yeast (42\%), A. niger (8\%), S. apiospermum (8\%). 
Those isolated from C. megacephala were identified as: Mucorales (18\%), Yeast (18\%), A. niger (36\%), Penicillium spp. (9\%), Cladosporium spp. (9\%) and Nocardia spp. $(9 \%)$.

\section{Warinchamrap district}

Fungi isolated from $M$. domestica were identified as: Mucorales $(18 \%)$, Yeast (18\%), A. niger (9\%), Penicillium spp. (18\%), A. fumigates (14\%), Gliocladium spp. (5\%), Fusarium spp. (9\%), Drechslera spp. (5\%) and Curvularia spp. (5\%).

Fungi identified from C. megacephala were: Mucorales (42\%), $A$. niger (17\%), Penicillium spp. (8\%), Gliocladium spp. (8\%), Fusarium spp. (8\%), Drechslera spp. (8\%), Curvularia spp. (8\%).

There was not a significant difference in the number of isolated fungal species between $C$. megacephala and $M$. domestica in Ubon Ratchathani province $(P=0.502)$. Fungi were isolated from over half of the collected $M$. domestica in Muang Ubon Ratchathani and Warinchamrap districts at 52.2 and $64.7 \%$ respectively. Less than half of the C. megacephala collected had fungi from Muang Ubon Ratchathani (47.8\%) and Warinchamrap (35.3\%) districts (Table-2).

Table 2- Comparison of fungi isolated from $M$. domestica and $C$. megacephala in Ubon Ratchathani province, Northeastern Thailand

\begin{tabular}{|c|c|c|c|}
\hline \multirow[b]{2}{*}{ Species } & \multicolumn{2}{|c|}{ Number of fungal isolates by site } & \multirow[b]{2}{*}{$\begin{array}{l}\text { Chi-square } \\
\text { (p-value) }\end{array}$} \\
\hline & $\begin{array}{l}\text { Muang Ubon } \\
\text { Ratchathani district }(\%)\end{array}$ & $\begin{array}{l}\text { Warinchamrap } \\
\text { district (\%) }\end{array}$ & \\
\hline \multirow{3}{*}{ M. domestica } & 12 & 22 & 0.450 \\
\hline & 52.2 & 64.7 & 0.502 \\
\hline & 11 & 12 & \\
\hline C. megacephala & 47.8 & 35.3 & \\
\hline
\end{tabular}

\section{Discussion}

We detected four genera/species of fungi from $M$. domestica in Muang Ubon Ratchathani district, Mucorales and Yeast were the most commonly isolated, and detected six genera/species of fungi from C. megacephala with the most prevalent species being $A$. niger. In Warinchamrap district, nine genera/species of fungi were detected from M. domestica with Mucorales, Yeast and Penicillium spp. being the most common groups isolated. Seven genera/ species of fungi were detected from C. megacephala in Warinchamrap district with Mucorales being the most prevalent.

In Warinchamrap district, there was a greater diversity of fungal species isolated than in Muang Ubon Ratchathani district. One explanation for this might be that in Warinchamrap district there might be a wider variety of substrates, favoring greater fungal diversity. Bergen and Wagner-Merner [21] also found that a greater number of fungal species found in determined places could be attributed to bioclimatic factors, favoring or interfering in the dispersion and survival of fungi. These authors also state that a greater number of substrates found in certain places can create favorable conditions for fungal growth.

We were observed that fungi isolates recovered were mostly saprophytes. However, some of genera or species were a pathogenic fungus that medical importance including;

Aspergillus spp. has been reported in nosocomial infections [22].

A. fumigates: Common human pathogen causing all forms of invasive and non-invasive aspergillosis. Cosmopolitan mould from soil and plant debris, but will grow on wide variety of substrates.
Mucorales: rare cause of human zygomycosis, mucormycosis is a rare opportunistic fungal infection of immunosuppressed patients. Most mucormycosis infections are life-threatening, and risk factors, such as diabetic ketoacidosis and neutropenia. Severe infection of the facial sinuses, which may extend into the brain, is the most common presentation. Pulmonary, cutaneous, and gastrointestinal (GI) infections are also recognized [22].

Fusarium: Rare opportunistic pathogen causing cutaneous and subcutaneous infections, mycotic keratitis, endophthalmitis, osteomyelitis, and arthritis following traumatic implantation. F. oxysporum, $F$. solani and $F$. moniliforme common soil fungi, with a world-wide distribution.

Cladosporium: Common fungi with a world-wide distribution. C. cladosporioides reported from a cutaneous infection in an immunosuppressed patient.

Curvularia: Rare cause of subcutaneous, sinusitis, endocarditis, peritonitis and disseminated infection in immunosuppressed patients. C. lunata, C. pallescens and C. geniculata are well documented human pathogens.

S. apiospermum: causing mycetoma, mycotic keratitis, arthritis and osteomyelitis due to traumatic implantation and invasive disseminated infections following inhalation of conidia such as sinusitis, pneumonia and brain abscesses. World-wide distribution from soil and plant debris.

Additionally, we collected flies from fresh-food markets, garbage piles, restaurants, school cafeterias and rice paddy fields where these places close association with human habitations and are capable of transmitting pathogenic fungus to human.

This study demonstrated that both the house fly; $M$. domestica and the blow fly; C. megacephala are carriers for fungal spores. Moreover, these flies might be important in the transmission of fungi to humans and animals in this area.

\section{Acknowledgements}

We thank the College of Medicine and Public Health, Ubon Ratchathani University, Muang Ubon Ratchathani, Thailand for facilities.

\section{References}

[1] Greenberg B. (1973) Flies and disease. Biological and disease transmission.

[2] Sucharit S., Tumrasvin W. and Vutikes S. (1976) J. Trop. Med. Public Health, 7, 85-90.

[3] Tumrasvin W., Sucharit S. and Kano R. (1978) Bull. Tokyo Med Dent., 25, 77-81.

[4] Sucharit S. and Tumrasvin W. (1981) J. Sanit. Zool, 32, 2815.

[5] Wells J.D. and Kurahashi H. (1994) J. Sanit. Zool, 45, 303-9.

[6] Kurahashi H. and Chowanadisai L. (2001) Species Divers, 6, 185-242.

[7] Tumrasvin W., Kurahashi H. and Kano R. (1979) Bull. Tokyo Med. Dent. Univ, 26, 243-72.

[8] Smith KGV. (1973) Insects and other arthropods of medical importance.

[9] Marcia de Senna Nunes Sales, Gisela Lara da Costa, Vania Rita Elias and Pinheiro Bittencourt (2002) Mem. Inst. Oswaldo. Cruz, Rio de janeiro, 97(8), 1107-1110.

[10]Hornick R.B., Greisman S.E. and Woodward T.E. (1970) N. 
Isolation of fungi from adult house fly; Musca domestica and the blow fly Chrysomya megacephala in Ubon Ratchathani Province, Northeastern Thailand

Eng. J. M. Fed, 69, 739-46.

[11]Gillian M., Prest D.B. and Morton H.L. (1974) J. Invert. Pathol, 24, 213-7.

[12]Costa G.L. and Oliveira P.C. (1998) J. Basic. Microbiol, 38, 343-7.

[13]Majid Aarrin, Babak Vaxirianzadeh, Setareh Shams Solary, Ali Zarei Mahmoudabadi and Mahmoud Rahdar (2007) Pak. J. Med. Sci, 23(6), 917-9.

[14]Burnside C.E. (1932) Bulletin Technical of U.S. Department Agriculture, 149-279.

[15]Gilliam M. and Prest D.B. (1972) J. Invert. Pathol, 20, 101103.

[16]Norberg A.N., Queiroz MMC., Maure EAP., Toledo R.F., Gazeta G.S., Norberg CMBM. and Guimarães R.R. (1999) XIV Congreso Latinoamericano de Parasitologia, 84.

[17]Kaaya G.P. and Okech M.A. (1990) Insect. Sci. Applic, 11, 443-448.

[18]Benjo A.D., Lawal O.A. and Adeduji O.O. (2005) Afr. J. Biotechnol, 4(8), 780-784.

[19]Benjo A.D., Lawal O.A. and Akintola O.I. (2006) Res. J. Agric. \& Biol. Sci, 2(6), 358-364.

[20]Arx JA Von (1981) J. Cramer, Vaduz, Germany, 3, 215.

[21]Bergen L. and Wagner-Merner D.T. (1977) Mycologia, 69, 299-308.

[22]Kontoyiannis D.P. and Lewis R.E. (2010) Mandell, Douglas and Bennett's Principles and Practice of Infectious Diseases. 7, 3257-69. 